\title{
The Efficacy of Mannitol Therapy in the Management of Moderate and Severe Forms of Ovarian Hyperstimulation Syndrome: A New Application
}

\section{A R T I C L E I N F O}

\section{Article Type}

Original research

\section{Authors}

Saremi A.T.* $M D$

Namdar Khanzadeh M. ${ }^{1}$

Pharm.D,

Shami M. ${ }^{2} B S C$

Mohammenad Aliha $\underline{F}^{2} \underline{B} \underline{S}$, Pooladi A. ${ }^{1} M D, P h D$

\section{A B S T R A C T}

Aims Ovarian hyperstimulation syndrome (OHSS) is an important complication of assisted reproductive technique (ART) following ovulation stimulation. Based on the disease pathophysiology and the mechanisms of drug effectiveness, mannitol was selected as an alternative for albumin. The objective of this study was to evaluate the efficacy of mannitol therapy in the management of moderate and severe forms of OHSS.

Materials \& Methods This interventional non-experimental study was conducted on patients with moderate and severe OHSS over a period of 19 years (1994-2013). A total of 6970 women entered the ovarian stimulation protocol for IVF. All patients at risk for OHSS received a preventive dose of mannitol. If the patients developed signs of moderate/severe OHSS, they included in the study. Mannitol therapy was started daily or twice a day using doses ranged between 1 to $1.5 \mathrm{~g} / \mathrm{kg} /$ dose. Patients were monitored according to the standard protocols. Data were analyzed by SPSS 19 software.

Findings OHSS developed in 1737 (24.92\%) women. Mild OHSS was found in 1360 (78.30\%), moderate in 338 (19.46\%), and severe in 39 (2.24\%) patients. A significant weight loss $(p=0.024)$ was found after mannitol therapy. The correction of mean intake/output (I/O) balance of fluids $(\mathrm{p}=0.009)$ showed significant difference before and after mannitol therapy. Mean duration of hospitalization was $4.72 \pm 2.24$ days, and the mortality rate was $0.0 \%$.

Conclusion Mannitol therapy is an effective protocol in the management of moderate and severe forms of OHSS.

Key words Ovarian Hyperstimulation Syndrome (OHSS); Management; Mannitol; Therapy; Efficacy
*Sarem Fertility \& Infertility Research Center (SAFIR) and Sarem Cell Research Center (SCRC), Sarem Women's Hospital, Tehran, Iran ${ }^{1}$ Sarem Fertility \& Infertility Research Center (SAFIR) and Sarem Cell Research Center (SCRC), Sarem Women's Hospital, Tehran, Iran ${ }^{2}$ Sarem Fertility \& Infertility Research Center (SAFIR), Sarem Women's Hospital, Tehran, Iran

\section{Correspondence}

Address: Sarem Women's Hospital, Basij Square, Phase 3, Ekbatan Town, Tehran, Iran. Postal Code: 1396956111

Phone: +98 (21) 44670888

Fax: +98 (21) 44670432

saremiat@yahoo.com

\section{Article History}

Received: April 3, 2016

Accepted: January 9, 2016

ePublished: October 20, 2017

\section{T A T I O N L I N K S}

[1] Symposium: Update on prediction and management of ... [2] Cabergoline for preventing ovarian hyperstimulation ... [3] Ovarian Hyperstimulation ... [4] Prevention of ovarian hyperstimulation syndrome in GnRH agonist IVF cycles in moderate risk patients: Randomized study comparing hydroxyethyl starch versus cabergoline and ... [5] Ovarian Hyperstimulation syndrome: Modern ... [6] Ovarian Hyperstimulation syndrome: A current ... [7] Transcapillary fluid dynamics during overian stimulationfor in vitro ... [8] The role of vascular endothelial growth factor and interleukins in the pathogenesis of ... [9] Role of vascular endothelial ... [10] Patterns of expression of vascular endothelial ... [11] Serum vascular endothelial growth factor (VEGF) in the normal menstrual cycle: Association with changes in ovarian and uterine ... [12] Vascular endothelial growth ... [13] Textbook of in vitro fertilization and assisted ... [14] Value of serum and follicular fluid cytokine profile in the prediction of moderate ... [15] Direct correlation between plasma ... [16] Ovarian hyperstimulation syndrome ... [17] The use of intravenous albumin in patients at high risk for severe ... [18] Decreased incidence of severe ovarian ... [19] Intravenous albumin prevents moderate-severe ... [20] The detrimental role of colloidal ... [21] Ovarian hyperstimulation .. [22] Can dopamine agonists reduce ... [23] Intra-venous fluids for the prevention of severe .. [24] Intravenous albumin does not prevent ... [25] Intravenous albumin administration .. [26] Administration of intravenous albumin ... [27] Sweeteners and sugar alternatives in .. [28] Drug infomation handbook: Comprehensive ... [29] Endocrine gland-derived vascular .. [30] Treatment of ovarian hyperstimulation ... [31] Administration of mannitol to prevent severe ... [32] Pathogenesis of ovarian hyperstimulation 
ريوى) اتفاق مىافتد كه ممكن است باعث تجمع مايعات در باتوريت

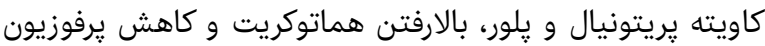

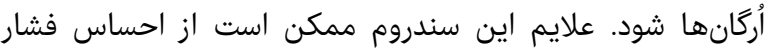

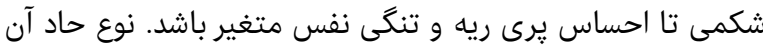

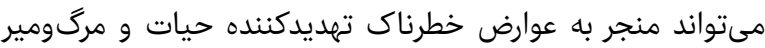

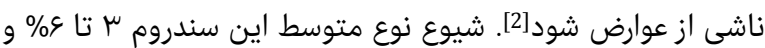

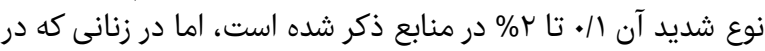

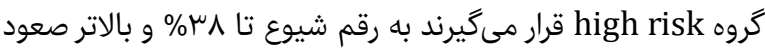

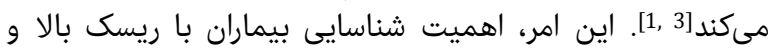

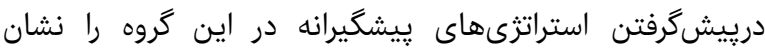

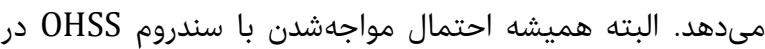

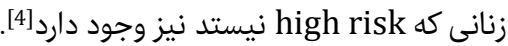

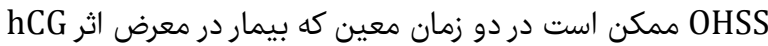
قرار مى

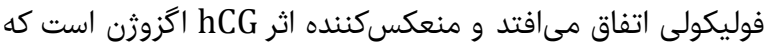

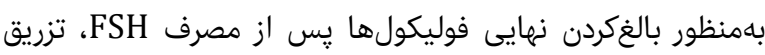

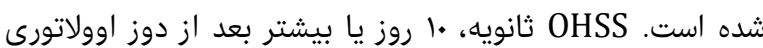

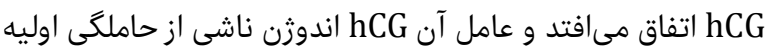

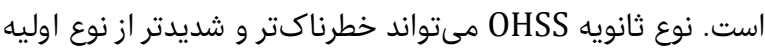

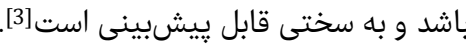

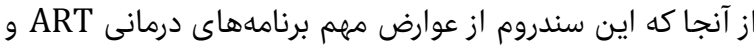

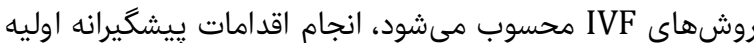

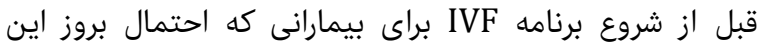

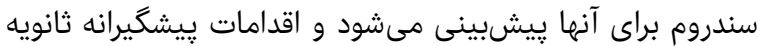

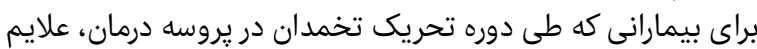

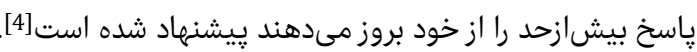

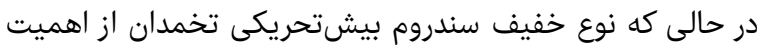

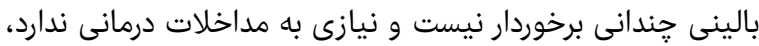

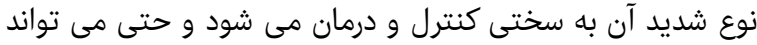

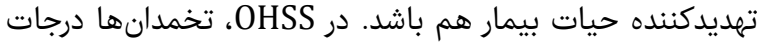

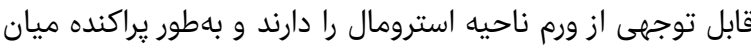

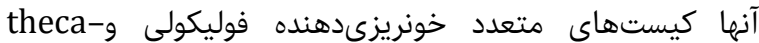
lutein

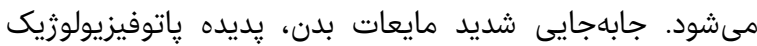

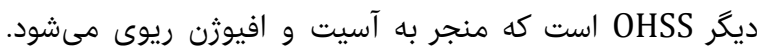

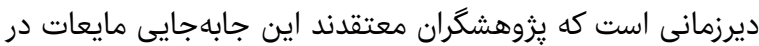

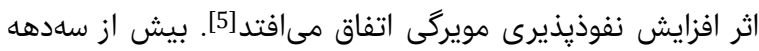

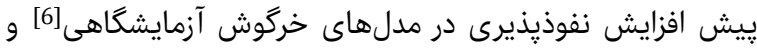

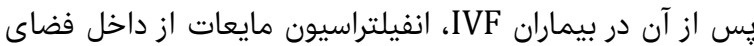

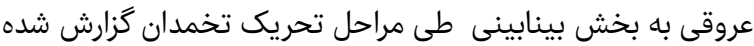

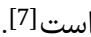

افزايش نفوذيذيرى عروق در اثر مواد وازواكتيوى است كه از

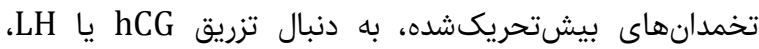

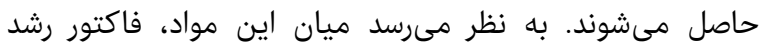

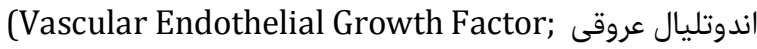

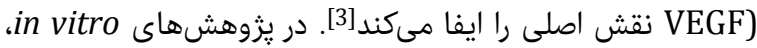

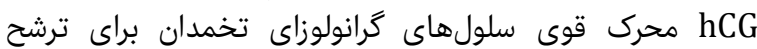

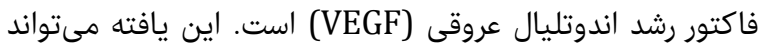

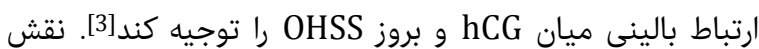

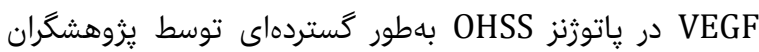

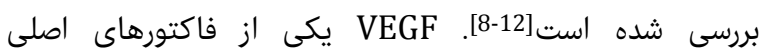

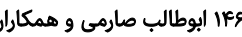

\section{بررسى اثربخشى مانيتول در مديريت نوع متوسط و شديد سندروم بيشتحريخي مانيتول تخرئمدان}

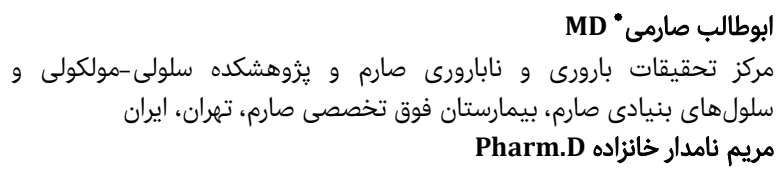

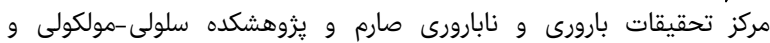
سلولهاى بنيادى صارم، بيمارستان فوق تخصصى صارم، تهرئ تهران، ايران

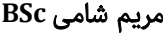
مركز تحقيقات بارورى و نابارورى صارم، بيمارستان فوق تخصصى صارم، تهران، ايران

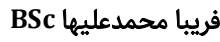
مركز تحقيقات بارورى و نابارورى صارم، بيمارستان فوق تخصصى صارم، تهران، إيران

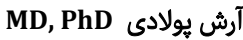

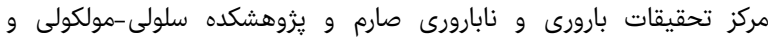
سلولهاى بنيادى صارم، بيمارستان فوق تخصصى صارئ تارم، تهران، ايران

جكيده

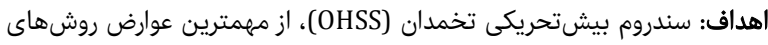

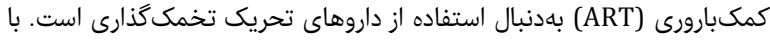

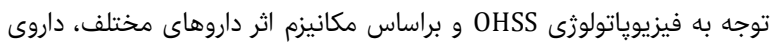

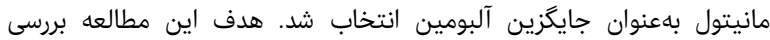

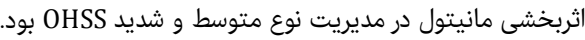

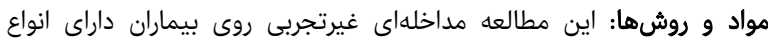

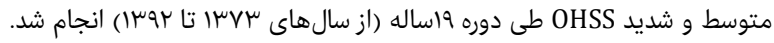

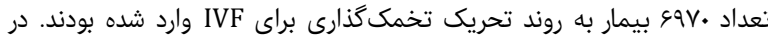

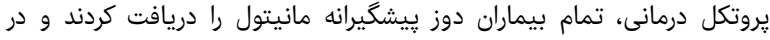

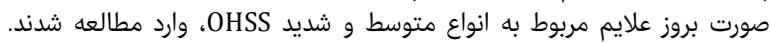

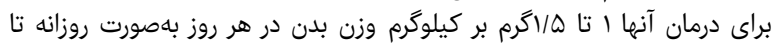

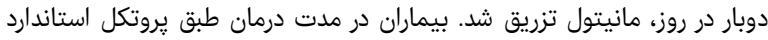

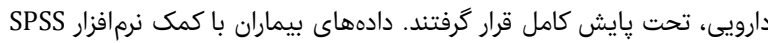

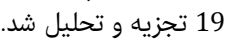

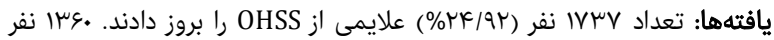

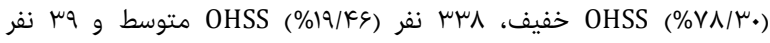

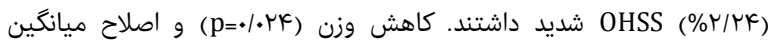

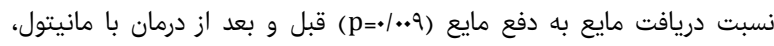

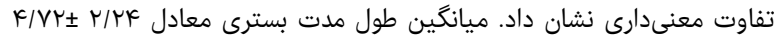

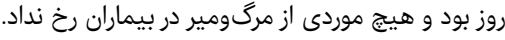

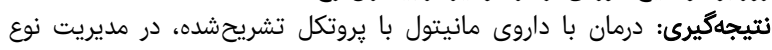

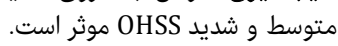
كليدواثزها: سندروم بيشتحريكى تخمدان (OHSS)، مديريت، مانيتول، درمان، اثربخشى

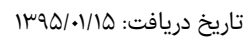

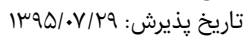

نويسنده مسئول: saremiat@yahoo.com

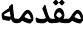

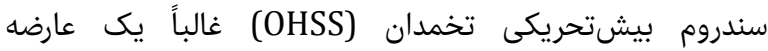

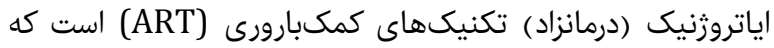
مىتواند يس از تحريك كنترلشده تخمدان (Controlled) Ovarian Hyperstimulation; COH)

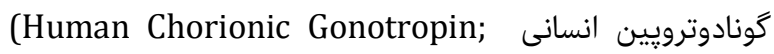

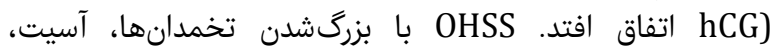

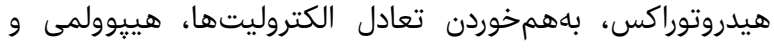

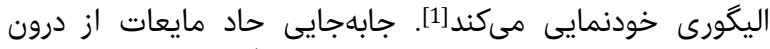

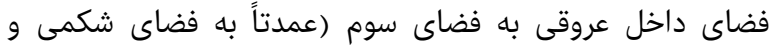




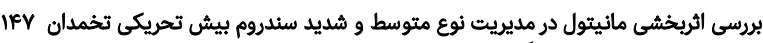

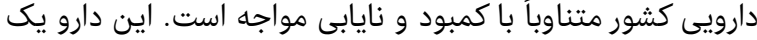

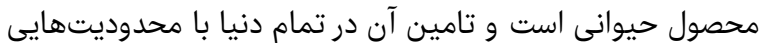

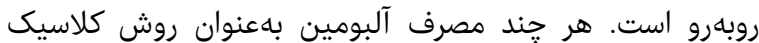

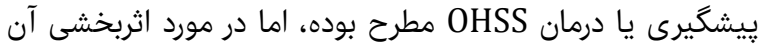

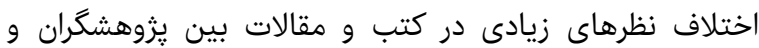

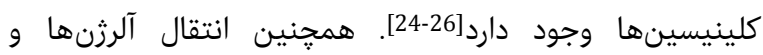

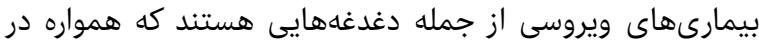

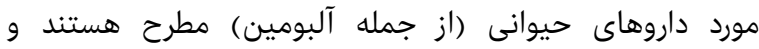

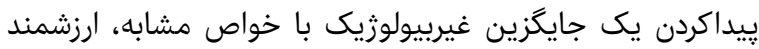
است]4]. مانيتول از نظر شيميايى، در كروه

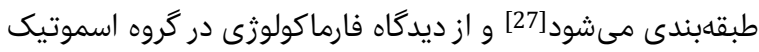

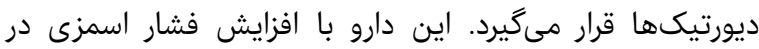

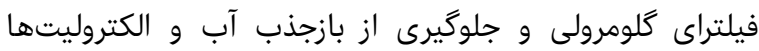

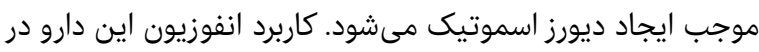

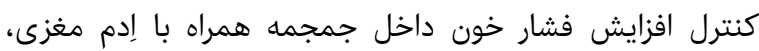

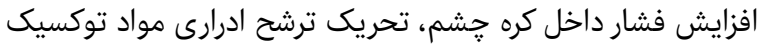

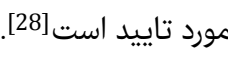

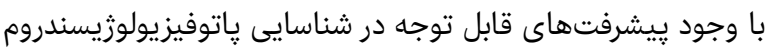
0HSS

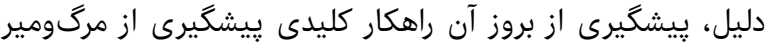

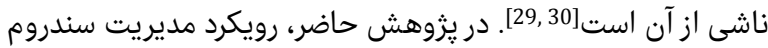

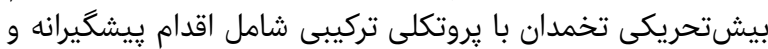

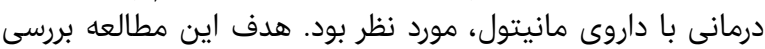

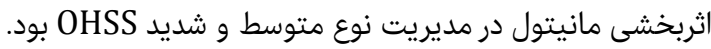

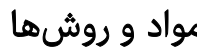

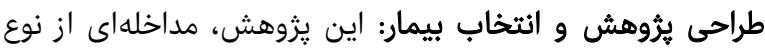

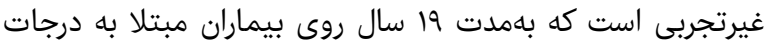

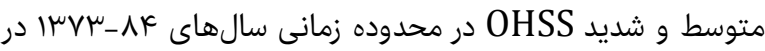

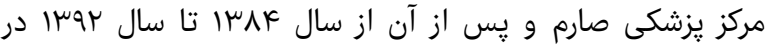

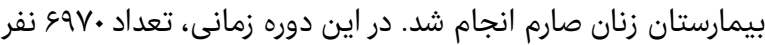

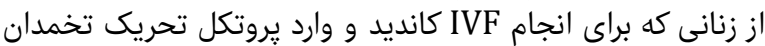

شده بودند، بررسى شدند.

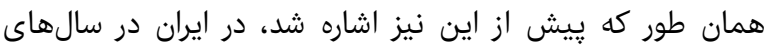

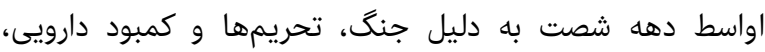

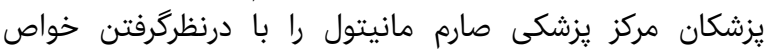

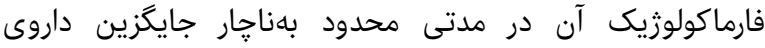

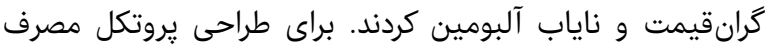

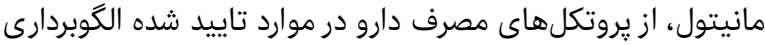

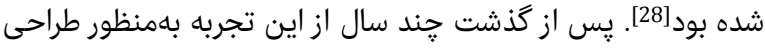

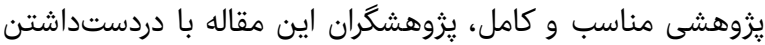

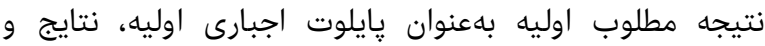

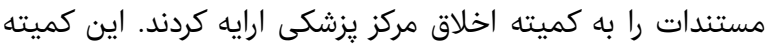

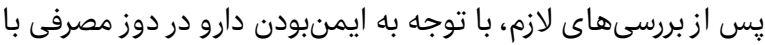

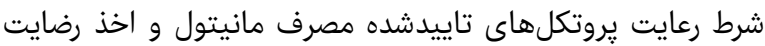

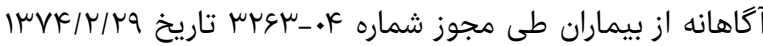

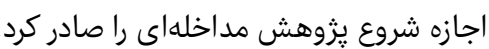

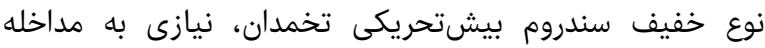

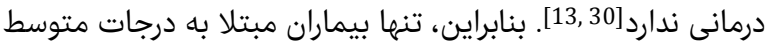

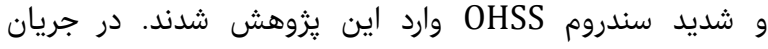

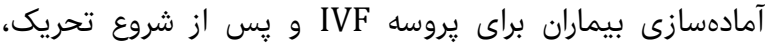

ايجادكننده افزايش نفوذيذيرى مويرگى در آسيت ناشى از OHSS

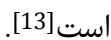

برخلاف نقش تعيينكننده hCG در ايجاد OHSS به نظر نمىرسد

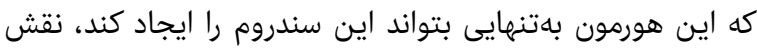

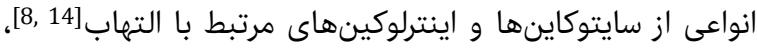

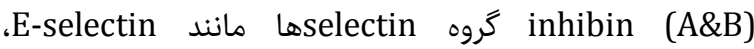
فاكتور Von Willebrand، تغييرات ايمونوگلوبولينها، تغييرات

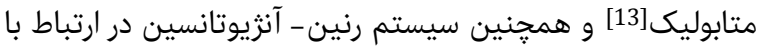
شدت و بروز OHSS به اثبات رسيده است

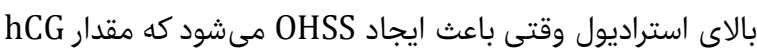

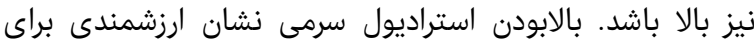

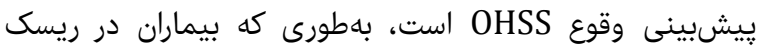
يHSS

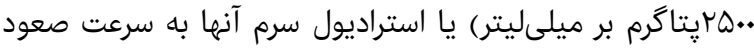

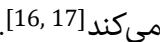

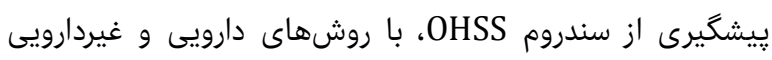

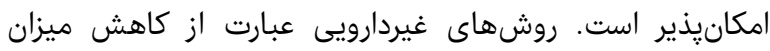
تحريك تخمدان، كاهش دوز BhCG، تاخير در تزريق مhCG

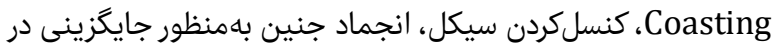

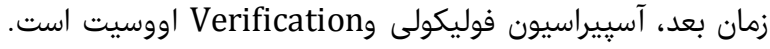

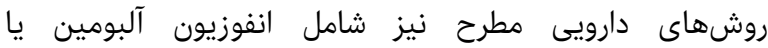

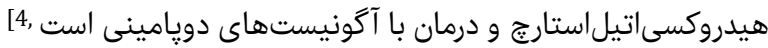

تزريق وريدى مايعات ممكن است منجر به تجديد حجم داخل

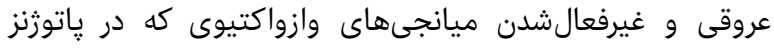
OHSS

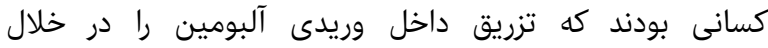
آسييراسيون فوليكولى بهمنظور يِيشگيرى از بروز

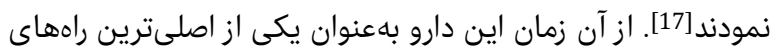

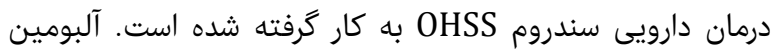

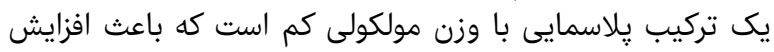
فشار اونكوتيك داخل عروق و حركت مايعات إيمائ از فضاى بينابينى به اسه

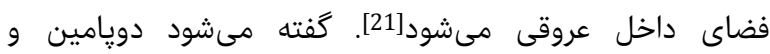

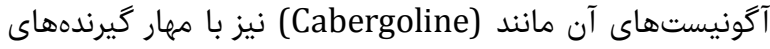

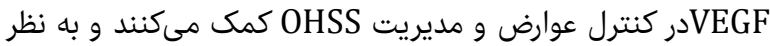

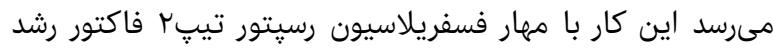

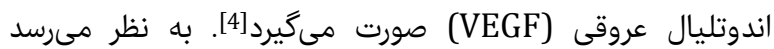

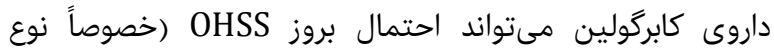

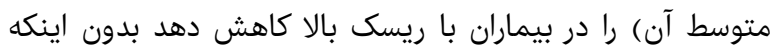

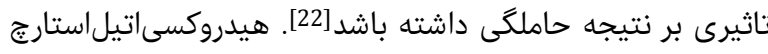
نيز با مكانيزم افزايش فشار (Hydroxy Ethyl Starch; HES)

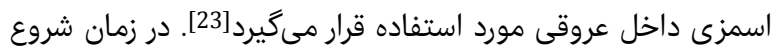

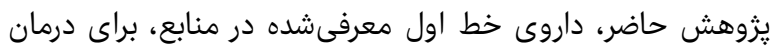

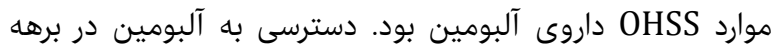

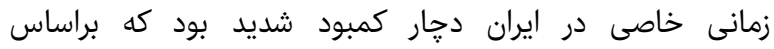

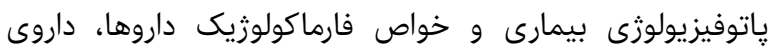

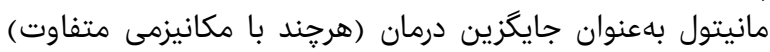

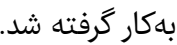

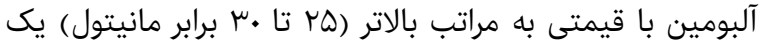

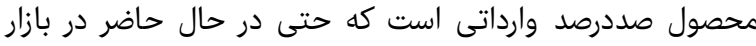


شود[28]. اين عوارض دارويى بهخصوص در مواردى كه با عوارض خارن

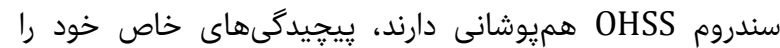

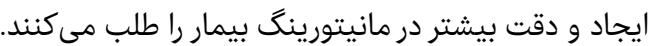

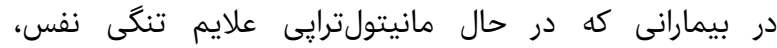

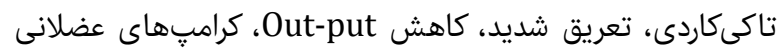

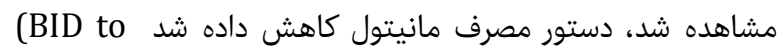
daily or daily to DC) به دليل كنترل احتمال آمبولى در بيماران، آزمون آزمايشكاهى D.Dimer

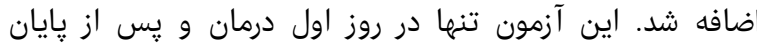
انفوزيون دارو انجام مى شود. بلهمنظور محاسبه فاصله اسمولار و براى ايمنى إنى بالاتر بيمار،

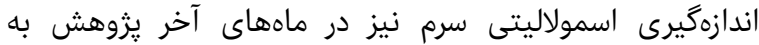

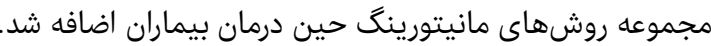

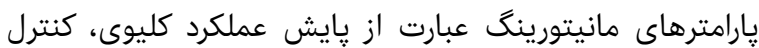

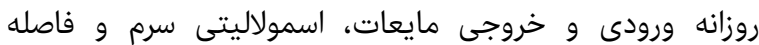

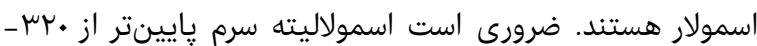

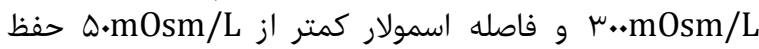

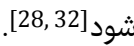
يروتكل مصرف مانيتول وريدى: براساس نظر كميته اجرايى إيى

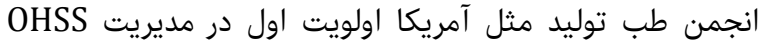

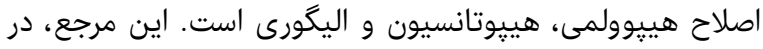

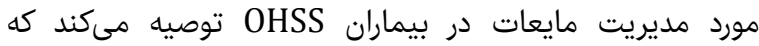

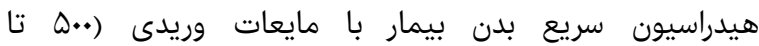

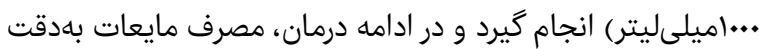

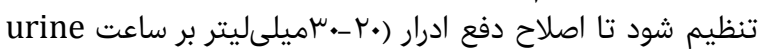

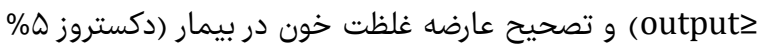

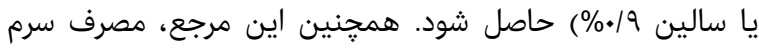

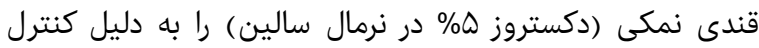

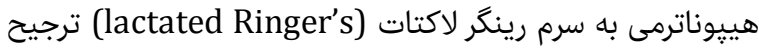

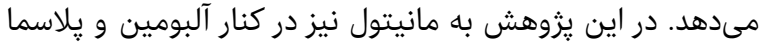

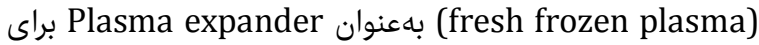

$$
\text { مديريت مايعات در بيماران OHSS اشاره شد [21]. }
$$

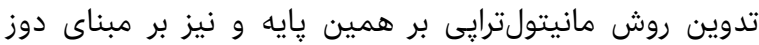

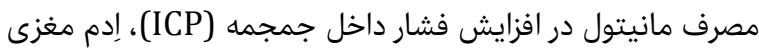

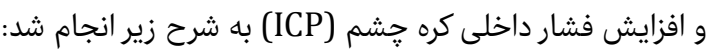

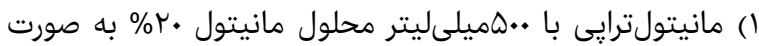

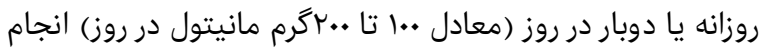

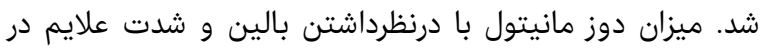

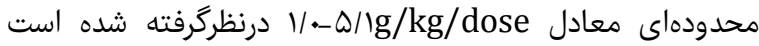

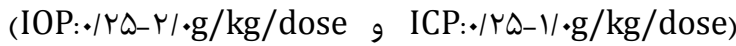

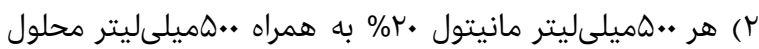

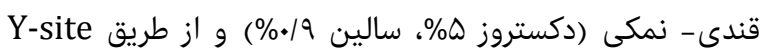

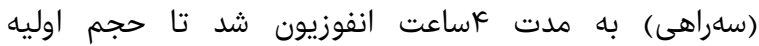

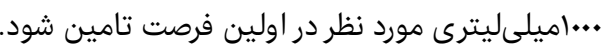

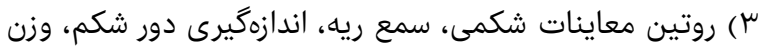

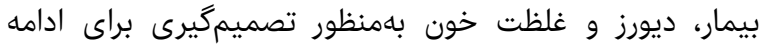

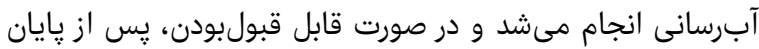

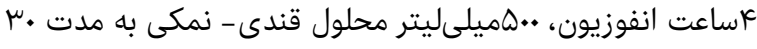

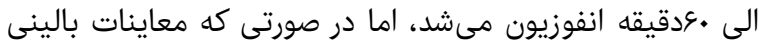

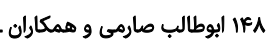

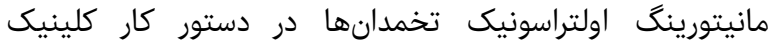

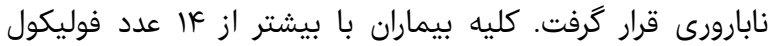

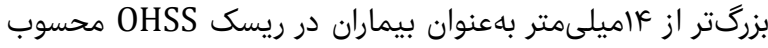

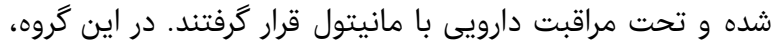

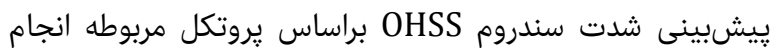

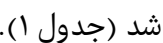

جدول () بروتكل بيشبيينى ابتلا به درجهانهاى متوسط تا شديد سندروم بيشتحريكى تخمدان براساس تعداد فوليكولها بئل

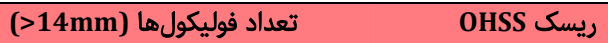

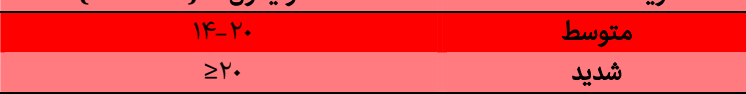

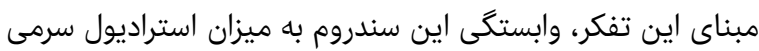

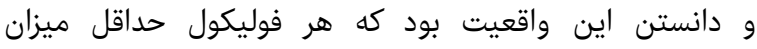

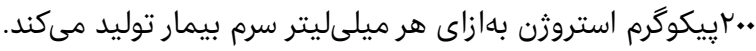

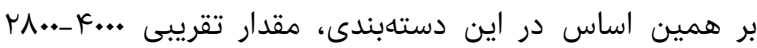

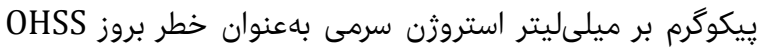

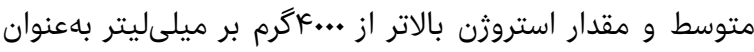

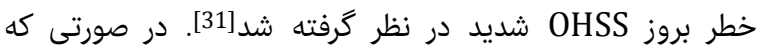

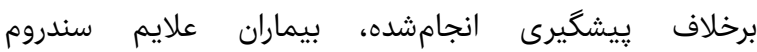

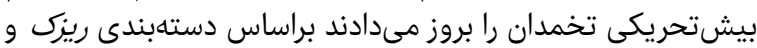

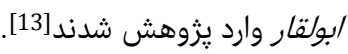

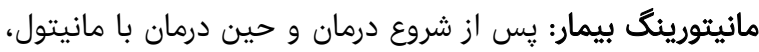

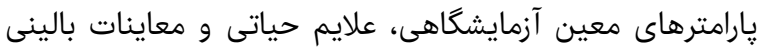

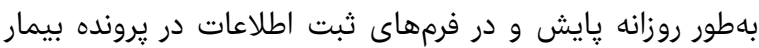

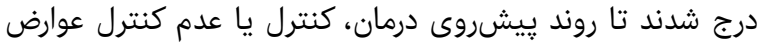

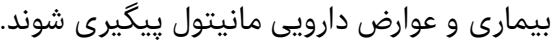

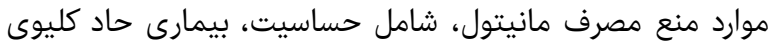

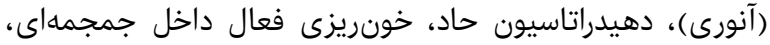

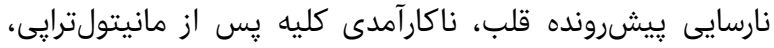

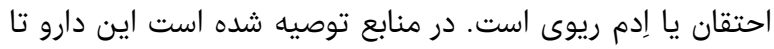

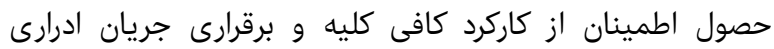

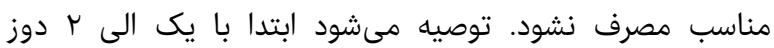

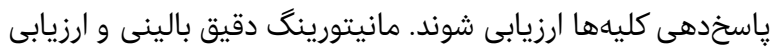

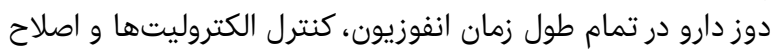

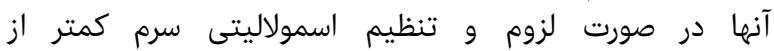

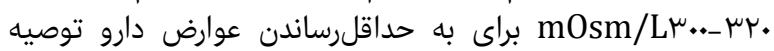

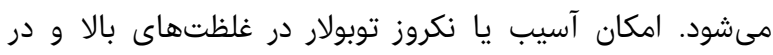

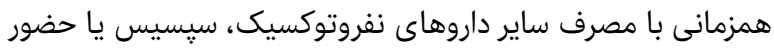

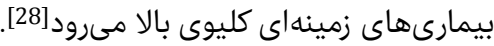
عوارض دارويى مانيتول شامل درد قفسه سيناله، نارئه نارسايى احتقانى

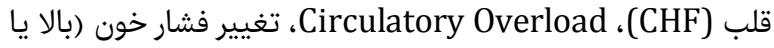

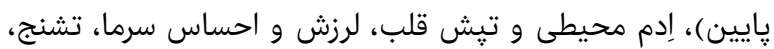

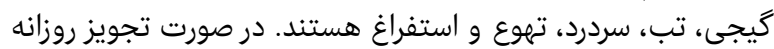

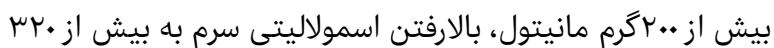

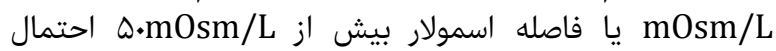

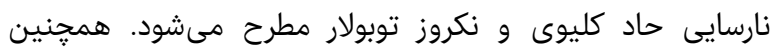

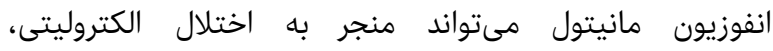

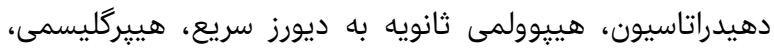

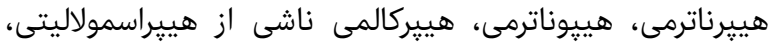

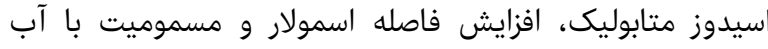


بررسى اثربخشى مانيتول در مديريت نوع متوسط و شديد سندروم بيش تحريكى تخمدان وزان

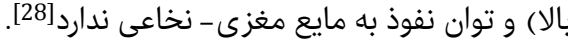

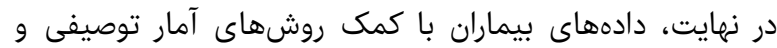
تحليلى توسط نرمافزار 19 SPSS تجزيه و دوائ تحليل شد.

يافتهها

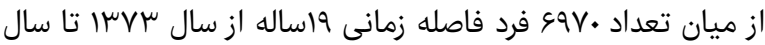

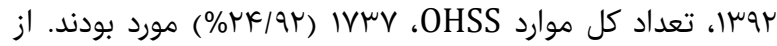

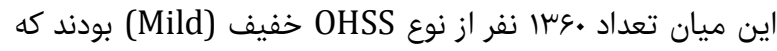

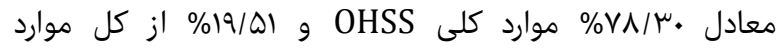

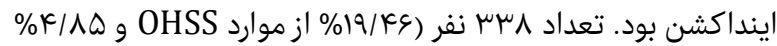

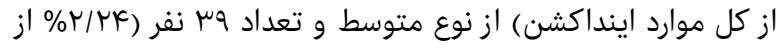

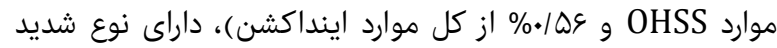

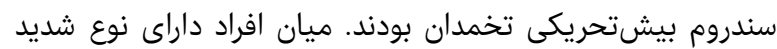
OHSS

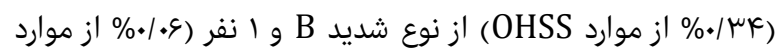

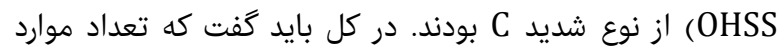
OHSS

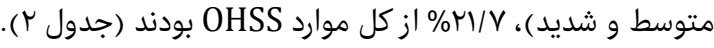

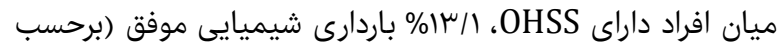

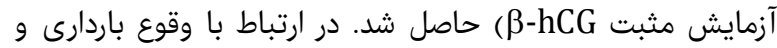

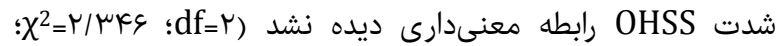

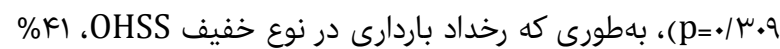

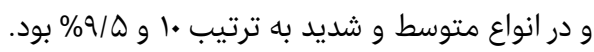

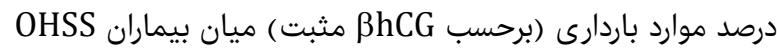

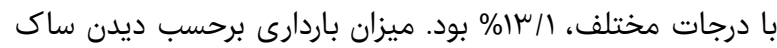

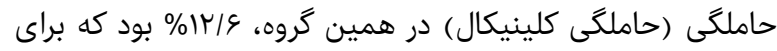

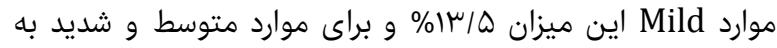

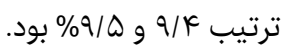

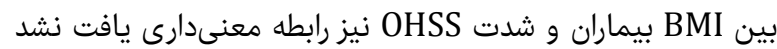

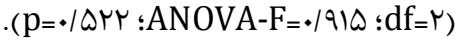

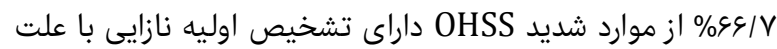

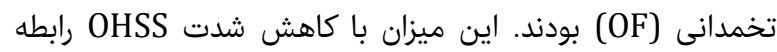
معنى
دلالت بر ييشروى احتباس مايعات در بدن بيمار داشت، اين

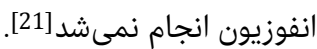

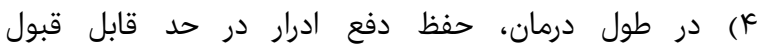

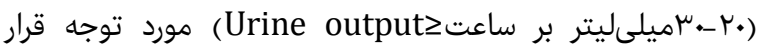

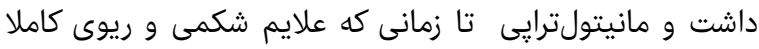

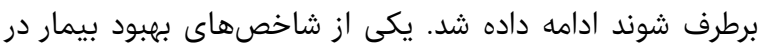

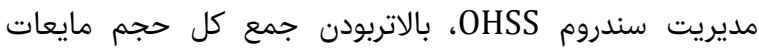

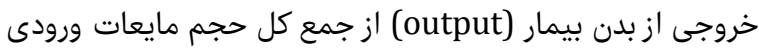

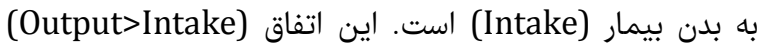

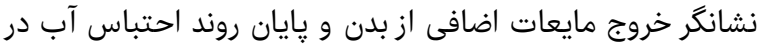

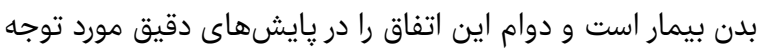

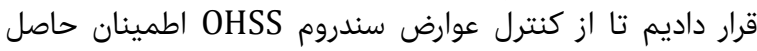

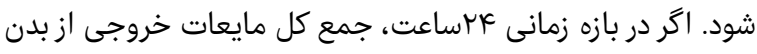

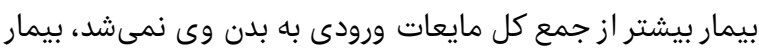

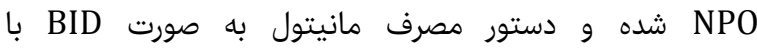

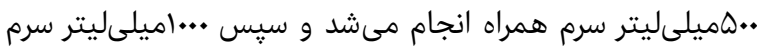

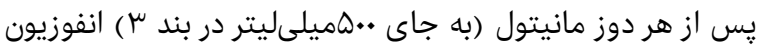

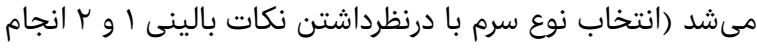

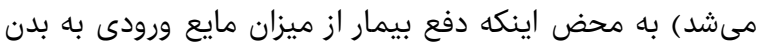

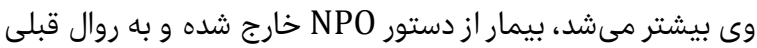

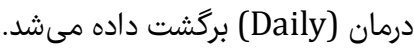

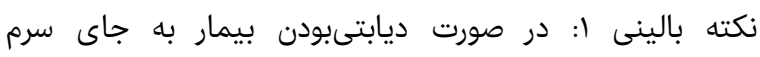

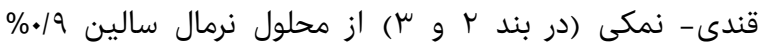

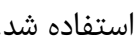

نكته بالينى r ب: براساس ميزان سديم سرمى بيمار و در صورت بروز

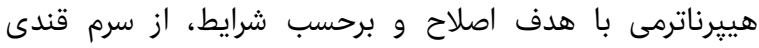

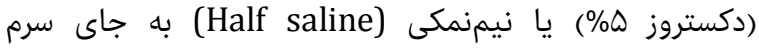

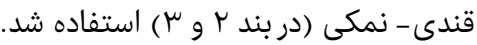

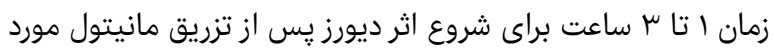

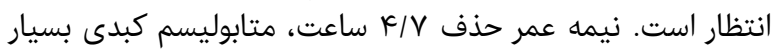

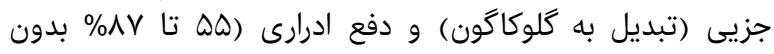

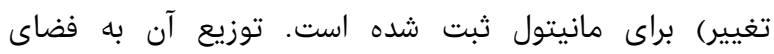

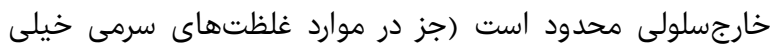

جدول r) تعداد بيماران مورد يزوهش و نتايج درمان با يروتكل مانيتول در آنها

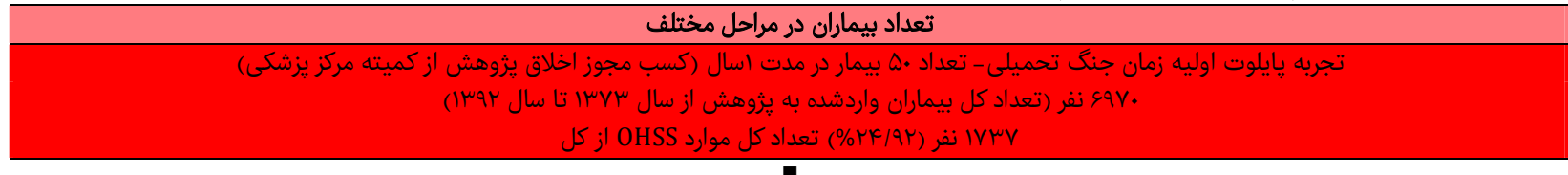

$\checkmark$

\begin{tabular}{|c|c|c|}
\hline \multicolumn{3}{|c|}{ تعداد بيماران مبتلا به OHSS براساس درجات بيمارى } \\
\hline وس نفر (OHSS شديد) & גس نفر (OHSS متوسط) & ع برا نفر (OHSS خفيف). \\
\hline 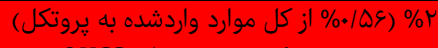 & & \\
\hline 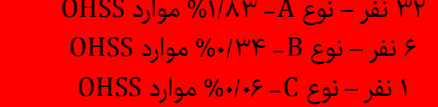 & 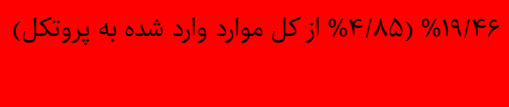 & 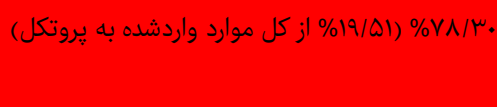 \\
\hline
\end{tabular}

7

نتايج درمان با مانيتول

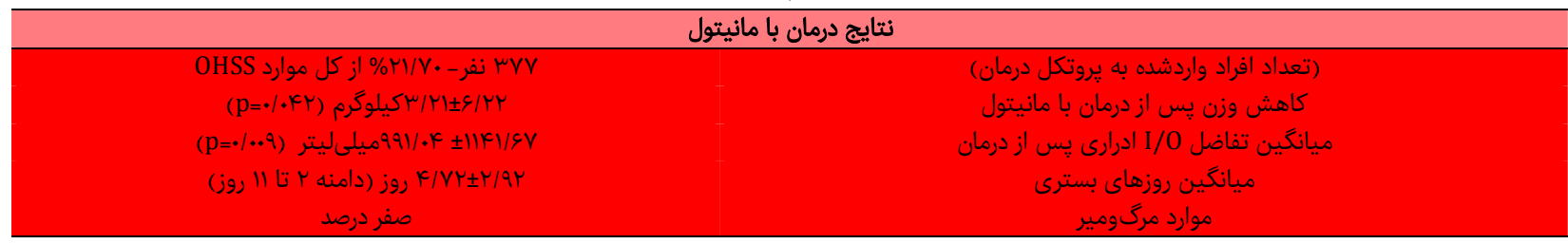


انجام نشده و ميزان مانيتول دريافتى بيش از حد مجاز توصيه شده

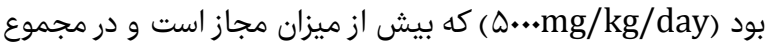

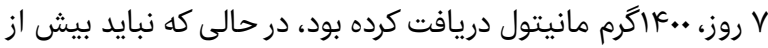

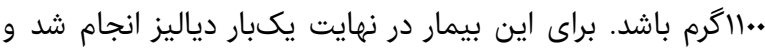

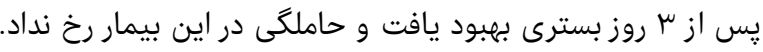

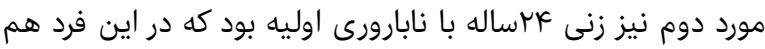

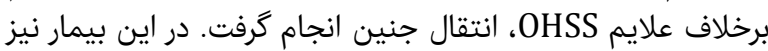

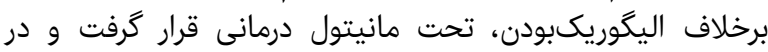

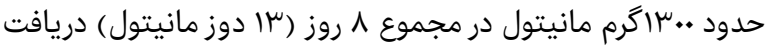

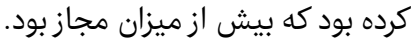

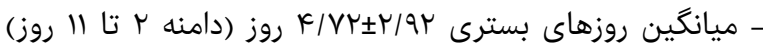

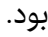

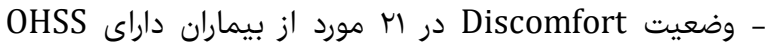

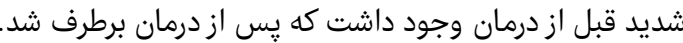

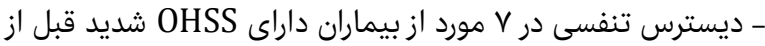
درمان وجود داشت كه بعد از درمان در همكى آنان، ديسترس النان برطرف شد

بحث

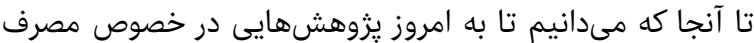

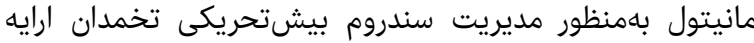

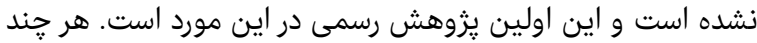

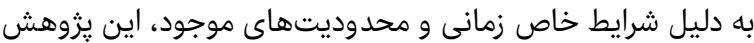

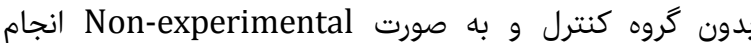

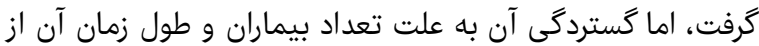

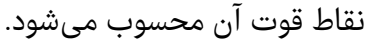

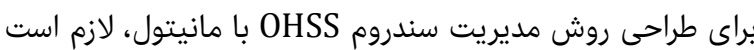

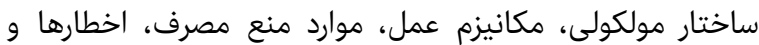

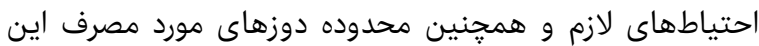

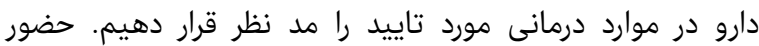

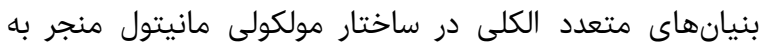

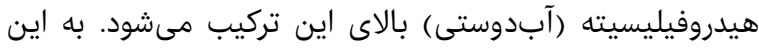

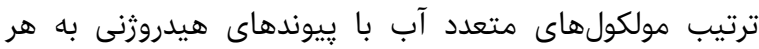

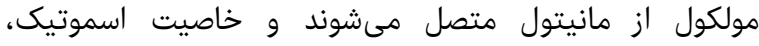
ديورتيك اين مولكول را ايجاد مىكنيند.

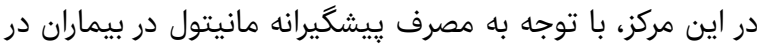

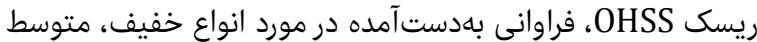

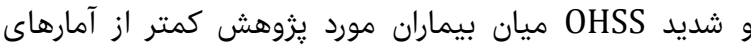

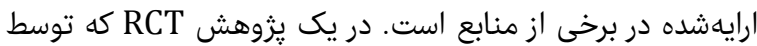

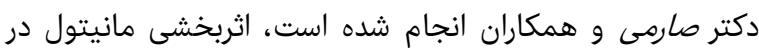

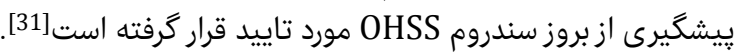

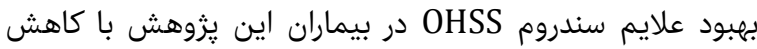

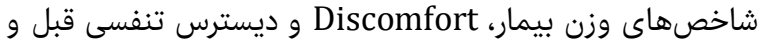

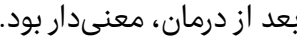

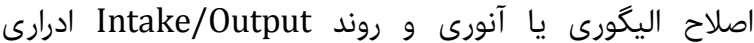

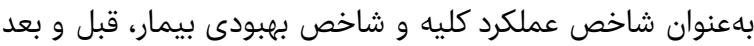

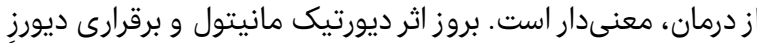

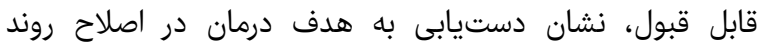

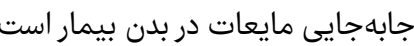

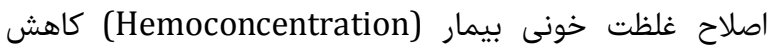
هماتوكريت و هموگلوبين قبل و بعد از درمان با مانيتول وجود دارد

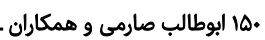

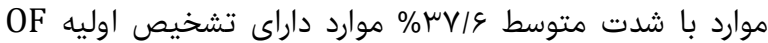

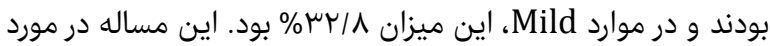

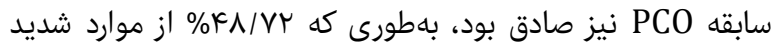
داراى تشخيص قبل PCO بHSS

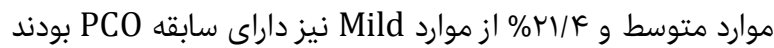

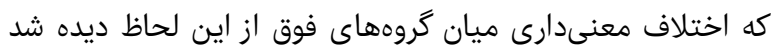
PC

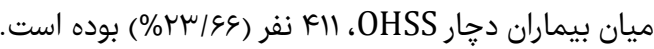

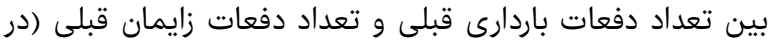

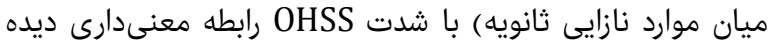

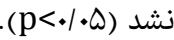

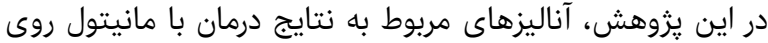

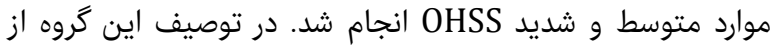

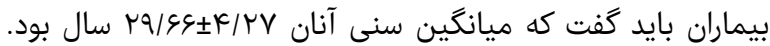

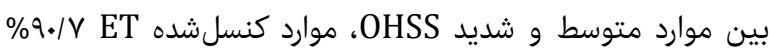

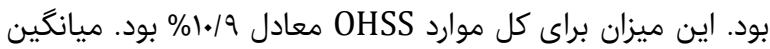

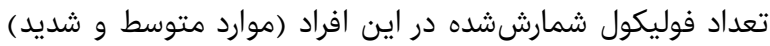

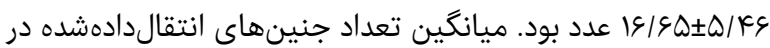

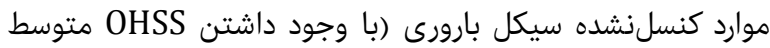

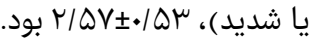

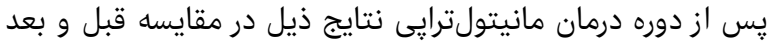

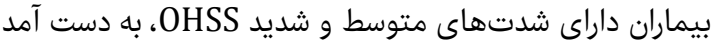

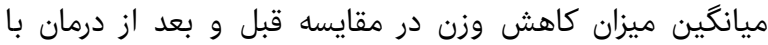

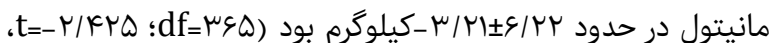

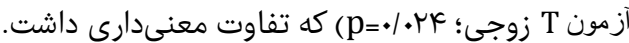

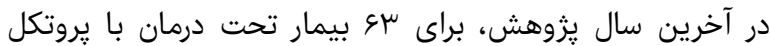

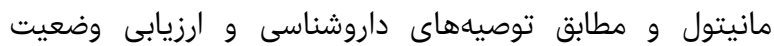

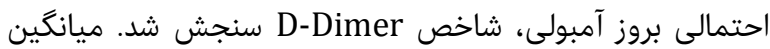
D-Dimer

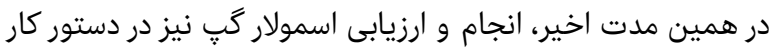

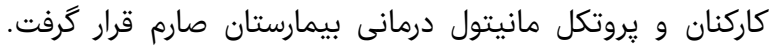

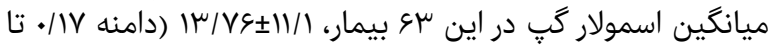

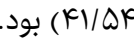

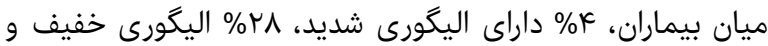

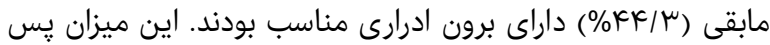

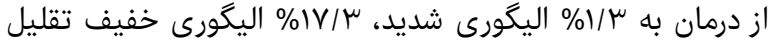

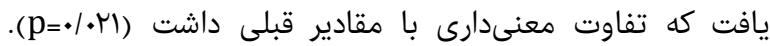

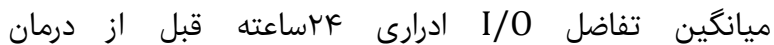
 آماري/DF

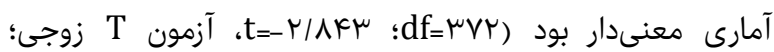

$$
\text { ( } \mathrm{p}=\cdot \cdot \text { 9 }
$$

هيج موردى از مركگمير در ميان بيماران درمانشده با يروتكل

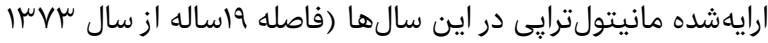

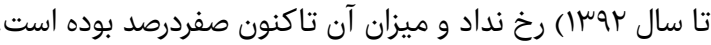

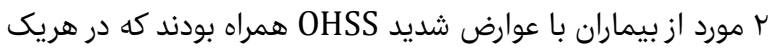

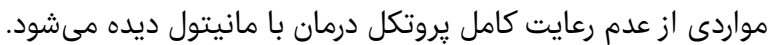

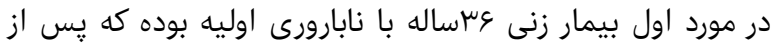

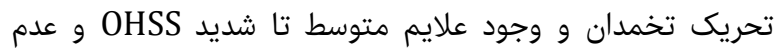

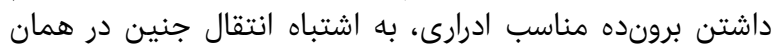
سيكل صورت گرفت و كنسل نشد. براى اين بيمار يروتكل به خوبى دربى درن 


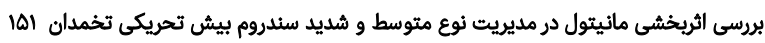

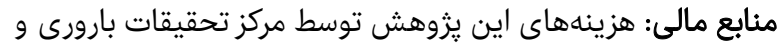

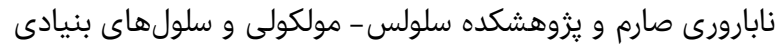
صارم تامين شده است سهم نويسندگان: ابوطالب صارمى (نويسنده اول)، نكارنده مقاله/

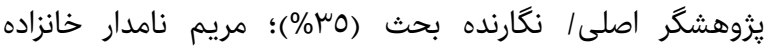

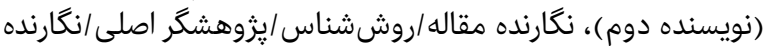

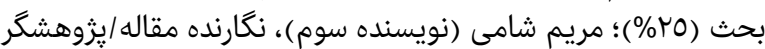

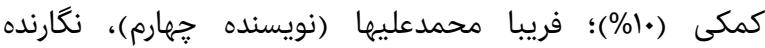

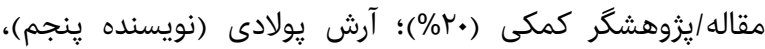

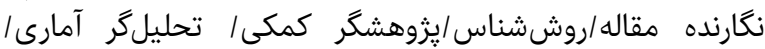

1- Aboulghar M. Symposium: Update on prediction and management of OHSS. Reprod Biomed Online. 2009;19(1):33-42.

2- Tang H, Hunter T, Hu Y, Zhai SD, Sheng X, Hart RJ. Cabergoline for preventing ovarian hyperstimulation syndrome. Cochrane Database Syst Rev. 2012;(2):CD008605.

3- Prakash A, Mathur R. Ovarian Hyperstimulation Syndrom. Obstet Gynecol. 2013;15:31-5.

4- Matorras R, Andres M, Mendoza R, Prieto B, Pijoan JI, Exposito A. Prevention of ovarian hyperstimulation syndrome in GnRH agonist IVF cycles in moderate risk patients: Randomized study comparing hydroxyethyl starch versus cabergoline and hydroxyethyl starch. Eur J Obstet Gynecol Reprod Biol. 2013;170(2):439-43.

5- Aboulghar MA, Mansour RT, Serour GI, et al. Ovarian Hyperstimulation syndrome: Modern consepts in pathophysiology and management. Middle East Fertil Soc J. 1996;1:3-16.

6- Schrenker J, Weinsten D. Ovarian Hyperstimulation syndrome: A current survey. Fertil Steril. 1978;30(3):255-68

7- Tollan A, Holst N, Forsdahl F, Fadnes HO, Oian P, Maltau JM. Transcapillary fluid dynamics during overian stimulationfor in vitro fertilization. Am J Obstet Gynecol. 1990;162(2):554-8.

8- Rizk B, Aboulghar M, Smitz J, Ron-El R. The role of vascular endothelial growth factor and interleukins in the pathogenesis of severe ovarian hyperstimulation syndrome. Hum Reprod Update. 1997;3(3):255-66.

9- Levin ER, Rosen GF, Cassidenti DL, Yee B, Meldrum D, Wisot A, et al. Role of vascular endothelial cell growth factor in Ovarian Hyperstimulation Syndrome. J Clin Invest. 1998;102(11):1978-85.

10- Shweiki D, Itin A, Neufeld G, Gitay-Goren H, Keshet E. Patterns of expression of vascular endothelial growth factor (VEGF) and VEGF receptors in mice suggest a role in hormonally regulated angiogenesis. J Clin Invest. 1993;91(5):2235-43.

11- Agrawal R, Conway GS, Sladkevicius P, Payne NN, Bekir J, Campbell S, et al. Serum vascular endothelial growth factor (VEGF) in the normal menstrual cycle: Association with changes in ovarian and uterine Doppler blood flow. Clinical Endocrinol. 1999;50(1):101-6.

12- McClure N, Healy DL, Rogers PA, Sullivan J, Beaton L, Haning RV Jr, et al. Vascular endothelial growth factor as capillary permeability agent in ovarian hyperstimulation syndrome. Lancet. 1994;344(8917):235-6.
هرجند از نظر آمارى معنىدار نيست، اما بايد به اين نكته توجه

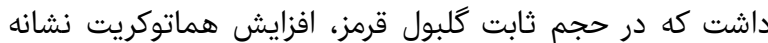

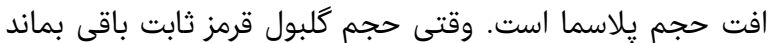

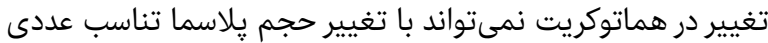

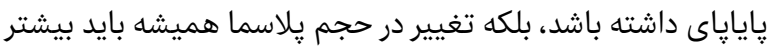

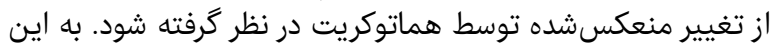

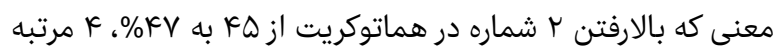

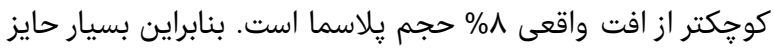

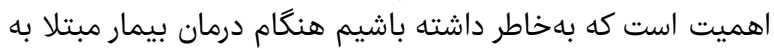
OHSS

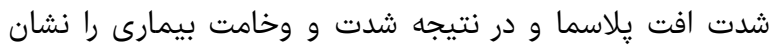

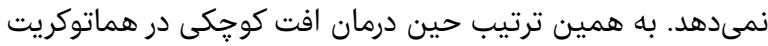

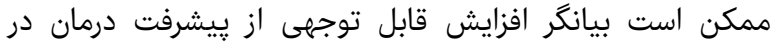

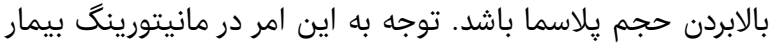

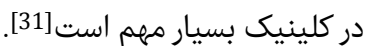

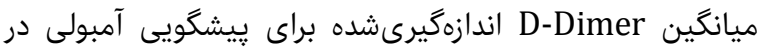
بيماران تحت درمان در محدوده ايمن است اندئ

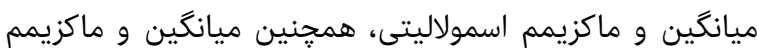

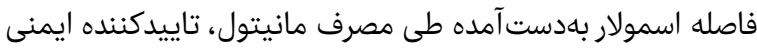

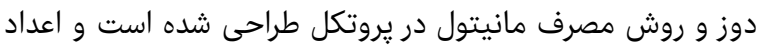

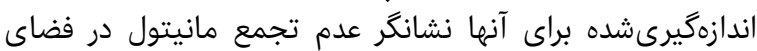

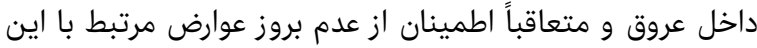
تجمع است. ميانگين تعداد روزهاى بسترى گزارش شده در بيماران اين يزوهش،

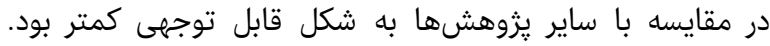

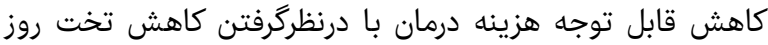

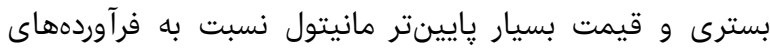

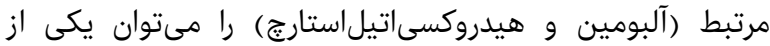

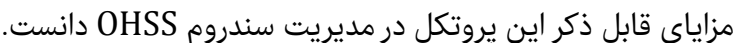

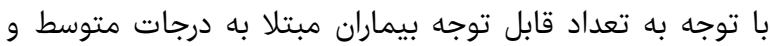

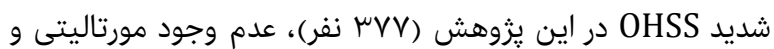

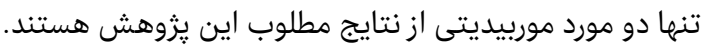

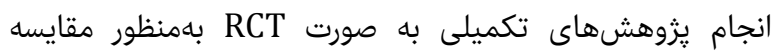

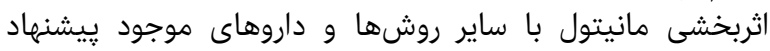

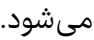

\section{نتيجه}

درمان با داروى مانيتول با تروتكل تشريحشده، در مديريت نوع

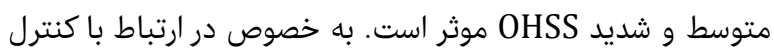

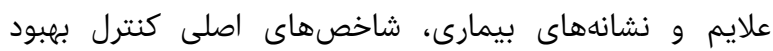

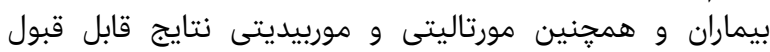
هستند. - يهار

تشكر و قدردانى: از زحمات ارزشمند سركار خانم ليلا زند آزاد در

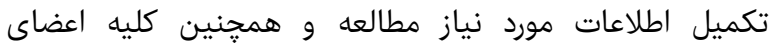

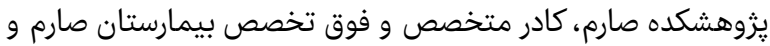

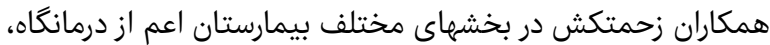

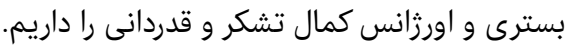

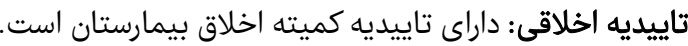

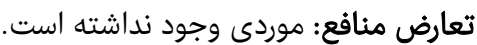


23- Youssef MA, Al-Inany HG, Evers JL, Aboulghar M. Intra-venous fluids for the prevention of severe ovarian hyperstimulation syndrome. Cochrane Database Syst Rev. 2011;2:CD001302.

24- Bellver J, Munoz EA, Ballesteros A, Soares SR, Bosch E, Simon C, et al. Intravenous albumin does not prevent moderate-severe ovarian hyperstimulation syndrome in high-risk IVF patients: A randomized controlled study. Hum Reprod. 2003;18(11):2283-8.

25- Venetis CA, Kolibianakis EM, Toulis KA, Goulis DG, Papadimas I, Tarlatzis BC. Intravenous albumin administration for the prevention of severe ovarian hyperstimulation syndrome: A systematic review and metaanalysis. Fertil Steril. 2011;95(1):188-96.

26- An SJ, Jee BC, Suh CS, Kim SH, Choi YM, Moon SY. Administration of intravenous albumin around the time of oocyte retrieval to prevent ovarian hyperstimulation syndrome: A meta-analysis. Fertility Steril. 2008;90 Suppl:S244-S5.

27- Kearsley MW, Kearsly MW, Deis RC, Malcom WM. Sweeteners and sugar alternatives in food technology, 2nd Edition. New Jersey: Blackwell publishing; 2006. pp. 249-61.

28- American Pharmacist Associaton. Drug infomation handbook: Comprehensive resource for all clinicians and healthcare professionals. Ohio: Lexicomp; 2012. 2387p.

29- Gao MZ, Zhao XM, Sun ZG, Hong Y, Zhao LW, Zhang HQ. Endocrine gland-derived vascular endothelial growth factor concentrations in follicular fluid and serum may predict ovarian hyperstimulation syndrome in women undergoing controlled ovarian hyperstimulation. Fertil Steril. 2011;95(2):673-8.

30- Aboulghar M. Treatment of ovarian hyperstimulation syndrome. Semin Reprod Med. 2010;28(6):532-9.

31- Saremi A, Alam M, Motaghi M. Administration of mannitol to prevent severe ovarian hyperstimulation syndrome : A randomized controlled trial. Middle East Fertil Soc J. 2003;8(2):159-63.

32- E Busso C, Soares SR, Pellicer A. Pathogenesis of ovarian hyperstimulation syndrome [Internet]. Alphen aan den Rijn: Wolters Kluwer Health. 1987. [updated Apr 2013; cited 2014 Jun 14]. Avilable from: https://www.uptodate.com/contents/pathogenesisclinical-manifestations-and-diagnosis-of-ovarianhyperstimulation-syndrome. 13- Brinsden PR. Textbook of in vitro fertilization and assisted reroduction: Informa healthcare. Milton Park: Taylor \& Francis; 2007. p. 688.

14- Chen C, Chen H, Lu H, Chen S, Ho H, YS Y. Value of serum and follicular fluid cytokine profile in the prediction of moderate to severe ovarian hyperstimulation syndrome. Hum Reprod. 2000;15(5):1037-42.

15- Navot D, Margalioth EJ, Laufer N, Birkenfeld A, Relou A, Rosler A, et al. Direct correlation between plasma renin activity and severity of the ovarian hyperstimulation syndrome. Fertil Steril. 1987;48(1):5761.

16- Nastri CO, Ferriani RA, Rocha IA, Martins WP. Ovarian hyperstimulation syndrome: Pathophysiology and prevention. J Assist Reprod Genet. 2010;27(23):121-8.

17- Asch RH, Ivery G, Goldsman M, Frederick JL, Stone SC, Balmaceda JP. The use of intravenous albumin in patients at high risk for severe ovarian hyperstimulation syndrome. Hum Reprod. 1993;8(7):1015-20.

18- Shalev E, Giladi Y, Matilsky M, Ben-Ami M. Decreased incidence of severe ovarian hyperstimulation syndrome in high risk in-vitro fertilization patients receiving intravenous albumin: A prospective study. Hum Reprod. 1995;10(6):1373-6.

19- Isik AZ, Gokmen O, Zeyneloglu HB, Kara S, Keles G, Gulekli B. Intravenous albumin prevents moderatesevere ovarian hyperstimulation in in-vitro fertilization patients: A prospective, randomized and controlled study. Eur J Obstet Gynecol Reprod Biol. 1996;70(2):17983.

20- Kissler S, Neidhardt B, Siebzehnrubl E, Schmitt H, Tschaikowsky $\mathrm{K}$, Wildt $\mathrm{L}$. The detrimental role of colloidal volume substitutes in severe ovarian hyperstimulation syndrome: A case report. Eur J Obstet Gynecol Reprod Biol. 2001;99(1):131-4.

21- Practice Committee of American Society for Reproductive Medicine. Ovarian hyperstimulation syndrome. Fertil Steril. 2008;90(Suppl 5):S188-93.

22- Youssef MA, Van Wely M, Hassan MA, Al-Inany HG, Mochtar M, Khattab S, et al. Can dopamine agonists reduce the incidence and severity of OHSS in IVF/ICSI treatment cycles? A systematic review and metaanalysis. Hum Reprod Update. 2010;16(5):459-66. 